\title{
DEVELOPMENT OF PROACTIVE METHOD OF COMMUNICATIONS FOR PROJECTS OF ENSURING THE ENERGY EFFICIENCY OF MUNICIPAL INFRASTRUCTURE
}

\author{
Sergey Bushuyev \\ Department of project management \\ Kyiv National University of Construction and Architecture \\ 31 Povitroflotsky ave., Kyiv, Ukraine, 03037 \\ sbushuyev@ukr.net \\ Maksym Shkuro \\ Department of project management \\ Kyiv National University of Construction and Architecture \\ 31 Povitroflotsky ave., Kyiv, Ukraine, 03037 \\ skuro_mu@meta.ua
}

\begin{abstract}
The analysis of scientific and practical approaches concerning the identification and classification of stakeholders, the definition of centers of influence on projects were carried out. It has been shown that there is insufficient attention paid to the aspects of proactive interaction with the stakeholders in the project management, the specificity of the projects for the ensuring of municipal energy efficiency is not taken into account. This article proposes to introduce the concept of the proactivity basis, identify the role of stakeholders of the municipal energy efficiency projects and the strength of their influence on the adoption of management decisions. The model of stakeholders of such projects is suggested taking into account the proactive influence on them. The model identifies stakeholders, their roles in municipal energy efficiency projects, and proposes appropriate proactive basis. The principles of proactive communication of the project of ensuring the municipal energy efficiency projects with stakeholders are formulated: the principle of common values, the principle of priority, the principle of continuous monitoring, the principle of feedback effectiveness, and the principle of strategic partnership. The method of proactive communication of the project management system is also developed, which will allow for proactive management of projects to ensure municipal energy efficiency.
\end{abstract}

Keywords: municipal energy efficiency projects, municipal infrastructure, project and program management, proactivity.

\section{Introduction}

At the present stage of development of managerial technologies, the organization's management understands that not only the volumes of manufactured products, their quality and manufacturability influence the organization's success. The perception of the organization by consumers, the media, certain social groups of the population, employees, etc. also plays a key role. The need for communication with stakeholder groups is recognized by organizations as an increasingly important managerial task.

Stakeholders are considered as groups of people (or organizations), whose contribution (work, capital, resources, purchasing power, etc.) is the basis of the organization's success.

Against the backdrop of continuous increases in energy tariffs, energy efficiency projects are becoming one of the top priorities, especially in the municipal sector. At the same time, prompt and efficient work of local governments (hereinafter - LG) with all stakeholders of such projects should contribute to the implementation of the energy strategy of Ukraine.

The project of increasing municipal energy efficiency, due to its high technological, social and economic significance, has a significant impact on the stakeholders. The importance of managing stakeholder relations is also emphasized by the fact that the relevant field of knowledge, along with the other nine, is singled out in one of the most commonly used PMBOK project management standards [1].

In addition to effective interaction with stakeholders of municipal energy efficiency projects (hereinafter - MEE project), in our opinion, appropriate proactive model and method need to be 
developed. They will provide LG with an opportunity not only to respond in a timely manner to changing stakeholder expectations but also to model their behavior.

Therefore, the development of a proactive model and method of energy efficiency projects of municipal infrastructure is an actual scientific and practical task.

\section{Literature review and problem statement}

Issues of stakeholder management developed in studies of scientists [2-9], but its application in municipal energy efficiency development projects is not sufficiently highlighted.

In [2] the experience of British organizations in focusing on different groups of project stakeholders in strategic planning is explored. The positive impact on performance indicators of such organizations has been shown, the necessity of identification and orientation of stakeholder groups has been proved. In general, the design of this approach in municipal energy efficiency projects can be applied, but performance indicators of the organization (LG) can't act as a determining factor for its assessment.

In order to study the application of different approaches to stakeholder management, in particular, work has been investigated [3]. This paper analyzes the application of two approaches to managing a stakeholder network: on the one hand, a classical approach to stakeholder management; on the other hand, management with one-sided problems (for example, a particular social group or a negative impact on the social aspect of the project) taking into account the expectations of another. Unfortunately, in our opinion, work does not take into account the specifics of energy efficiency projects. Combining two approaches to stakeholder management and focusing on specific issues with multidisciplinary management, will provide an opportunity for MEE projects to address complex problems, choose the optimal strategy for interaction with the network of stakeholders.

Due to some social significance of MEE projects it is also necessary to study the choice of methods for assessing and managing the reputation of the organization from the point of view of the external stakeholders of the project. These questions are devoted to work [4]. In this work, an analysis of the reputation of various financial organizations in the world is carried out and some tools for its simulation are presented - network analysis, histogram analysis according to different parameters. The results of the analysis provide a certain unified template for improving the reputation of the organization for the outside of the project. Network and histogram analysis based on the specific and parameters of MEE projects can serve as the starting point for the formation of a unified plan of measures to improve the reputation of LG within the framework of the energy efficiency strategy of Ukraine.

In work [5] models of system dynamics and centers of influence in development projects of organizations that can become an integral part of the modeling of stakeholder management modeling of municipal energy efficiency projects are developed. However, the work does not take into account the proactive component of the organization's role in relations with interested parties.

To form a network of MEE projects stakeholders, it is necessary to classify them. In particular, in [6], a classification of stakeholders is proposed for various features, spheres, and levels of influence. Some of these features may be taken into account in the further classification of MEE stakeholders.

The issue of managing work-related threats [7] should also be taken into account in municipal energy efficiency projects. The principles of counteracting the threats to securing the values of stakeholders in this work do not take into account MEE projects specifics but can be adapted and used in the future.

The consideration of the interaction of stakeholders in portfolio management in the context of regional development is researched in [8]. The main emphasis in the work is on the economic security of Ukraine. However, the following factors are not taken into account: proactivity, association of the organization's strategy with the main characteristics of the implementation of projects and their impact on the expectations of stakeholders. A separate development approach is needed to formalize the structure of portfolios, taking into account the specifics of energy efficiency.

The coherent aspect of managing stakeholders is the principle within which such a management is carried out - the principle of proactivity. Research on the application of the proactivity principle in management systems was carried out in the works of foreign scientists [9-11]. 
For example, in [9], studies have been conducted on certain groups of individuals with an active behavior towards the environment. On the basis of the psychological properties of individuals, factors determining the proactive nature of interaction with the environment have been identified. This study provides a basis for these aspects to be taken into account, taking into account the specificity of the MEE projects at the level of performers.

In more detail, and at the organizational level, the proactivity has been investigated in particular in [10]. The work analyzes four constructs related to the proactive behavior of six domains (directions). Unfortunately, the author does not take into account the specifics of behavior in organizations that use the methodology of project management.

Research of various types of proactive behavior is given in [11]. Three types of proactive behavior have been identified that have different directions, both in the middle of the organization and in the direction of the environment. In our opinion, such important aspects of behavior as stakeholder values have not been taken into account, but a factor analysis of project managers' self-assessment can be applied in MEE by analogy with [11].

One of the first domestic works on proactive research in the field of project management is work [12]. However, it only identifies general trends in the development of appropriate approaches. At the same time, these issues can be used in applied applications, including in municipal energy efficiency projects.

In [13], the proactive reaction of the organization to the change of some market parameters, for example, demand, level of competition and market needs has been investigated. Such an approach, in our opinion, does not sufficiently take into account the whole complex of expectations of the project stakeholders, both internal and external.

In [14] matrix technologies of proactive management of organizations' development are investigated, but specific aspects of the activities of LG are not taken into account.

The work on the use of data-mining techniques and information support for proactive management is devoted to work [15]. The main emphasis is placed on the processes of making managerial decisions, in particular in the information and analytical systems, but the issues of proactivity in portfolio management are not sufficiently researched.

The formation of the mechanism of proactive management is discussed in [16]. The proposed mechanism does not foresee the classification and analysis of stakeholder impacts of projects, portfolios and programs, taking into account uncertainty.

The use of a thermodynamic criterion analogy in projects to implement proactive management is explored in work [17]. The iterative nature of the implementation of projects, described in [17], is not appropriate for MEE projects. But, in our opinion, this approach is suitable to use only in the phase of initialization of such projects.

In [18], two aspects of the management system - stakeholder management and the proactivity principle are combined. Primary and secondary stakeholders have been identified, depending on the industry, expert data on their environmental impact are presented. The influence of the use of proactive strategies on the stakeholders of the project is described, but some recommendations, methods and models for the formulation of such strategies are not proposed.

The analysis of scientific sources reveals an unsolved part of the scientific problem in the field of energy efficiency, which can be formulated as follows. For now, proactive models and methods for improving the energy efficiency of municipal infrastructure objects have not been developed in terms of effective communication of the relevant projects with the interested parties.

\section{Purpose and objectives of the research}

The purpose of the article is studying the application of the proactivity principle in stakeholders' communications in municipal energy efficiency projects.

To achieve this purpose, the following tasks are set:

- apply the principle of proactivity of the project to increase the municipal energy efficiency with the project stakeholders, propose relevant definitions, identify possible stakeholder roles;

- build a model of stakeholders of the MEE project taking into account the proactive influence on them; 
- propose a method of proactive communication of the MEE project management system with the stakeholders.

\section{Materials and methods for researching proactive communication with stakeholders in the project}

Let's consider from the point of view of the described aspects of MEE projects a scientific tool for conducting proactive communication with stakeholders in the projects.

MEE projects determine their specific environment, which requires the identification of the major stakeholders. However, the application of the proactivity principle for stakeholder management of PME projects involves the formation of some interface between the proactive principle and subsystem of stakeholder management. In our opinion, such an interface should have a definition as proactivity basis.

Definition. Proactivity basis - the aspect or parameter of the activity of the project stakeholders, which can be influenced by the project management system in advance in order to direct the activities of the stakeholder in the project's support.

When identifying a stakeholder in the municipal energy efficiency project, the following parameters, such as its role and influence of the project, should be taken into account. This approach, in particular, provides the opportunity to integrate the results of the identification of stakeholders in the project into risk management plans and communications in MEE projects.

The role of an interested party in PME projects may be one of the following:

- Regulator. An authority that develops and/or approves regulatory acts on energy efficiency issues.

- Legislative initiative (hereinafter - the LI). A person or authority whose powers include the elaboration and approval of legislative acts on energy efficiency.

- Support. An authority that provides monitoring and monitoring of energy efficiency measures.

- Financing. An authority responsible for financing MEE project.

- Project management. A person or authority that uses the project approach in MEE.

- Implementation object. The object of the implementation of energy efficiency technologies.

- Supplier. Supplier of solutions and technologies for energy efficiency.

- Performer of work. A direct executor of activities for technologies and solutions implementation of energy efficiency at the facility.

- Service provider. A person or authority that provides consulting and independent assessment services for the transfer of energy-efficient technologies.

The influence of the stakeholder of the MEE project can be:

- High (H). The stakeholder may initiate a decision to terminate or extend the MEE project. Provides monitoring projects through the control milestones.

- Average (A). The stakeholder can influence the management and technical decisions of the MEE project. Responsible for delivering MEE project results.

- Low $(L)$. Has little influence on the technical and managerial decisions of the current MEE project. May initiate such decisions in future projects to ensure municipal energy efficiency.

The results of MEE project stakeholders' identification with the definition of the proactivity basis for each of them are shown in Table 1.

The goal of establishing communication with stakeholders of the MEE project is to increase the likelihood of staying of stakeholders on a sustainable project support path. To achieve this goal it is necessary to provide the appropriate ground. For this purpose, let's formulate the principles of implementing an effective proactive communication in MEE project with its stakeholders:

- principle of common values (the interest of each stakeholder in raising energy efficiency, the formulation of it in the form of value, the cultivation of this value as a common value with the MEE project); 
- principle of priority (when making decisions to be guided by the priority criterion of the attractiveness of solutions with an impact on energy efficiency);

- principle of continuous monitoring (periodic analysis or measurement of the stakeholder's relation to the MEE project, determination of the degree of support or resistance of the project by each stakeholder);

- principle of constancy and effectiveness of feedback (constant communication with stakeholders, receiving inquiries and sending answers, holding sessions of joint consideration of MEE project, an involvement of stakeholders to make key decisions in the project);

- principle of strategic partnership (stakeholders motivation to participate in the MEE project through the formulation of the possibility of a strategic partnership - involvement of the stakeholder in future MEE projects in case of successful cooperation within the current project).

\section{Table 1}

Model of stakeholders of the PME project taking into account the proactive influence on them

\begin{tabular}{|c|c|c|c|c|}
\hline No. & Stakeholder & Role in MEE project & $\begin{array}{c}\text { Influence on } \\
\text { the project }\end{array}$ & Proactivity basis \\
\hline 1 & Verkhovna Rada of Ukraine & Regulator & $\mathrm{H}$ & Law drafts \\
\hline 2 & President of Ukraine & Legislative initiative & $\mathrm{H}$ & Decisions drafts \\
\hline 3 & Cabinet of Ministers of Ukraine & Regulator & $\mathrm{H}$ & Decisions drafts \\
\hline 4 & Ministry of Regional Development & Regulator & $\mathrm{H}$ & Decisions drafts \\
\hline 5 & State agency for energy efficiency & Support & $\mathrm{H}$ & Decisions drafts \\
\hline 6 & Energy efficiency fund & Financing & A & Profitability of the project \\
\hline 7 & $\begin{array}{l}\text { Public Council of ministry of } \\
\text { Regional Development }\end{array}$ & Support & A & $\begin{array}{l}\text { A positive response in } \\
\text { society }\end{array}$ \\
\hline 8 & Local State Administration & Project management & $\mathrm{H}$ & $\begin{array}{l}\text { A positive response in } \\
\text { society }\end{array}$ \\
\hline 9 & Local community & Support & $\mathrm{H}$ & $\begin{array}{c}\text { Cost savings, community } \\
\text { development }\end{array}$ \\
\hline 10 & State and municipal enterprises & Implementation object & A & Profit, image \\
\hline 11 & $\begin{array}{l}\text { Association of co-owners of } \\
\text { multi-family houses }\end{array}$ & Implementation object & $\mathrm{L}$ & $\begin{array}{c}\text { Cost savings, development } \\
\text { of fixed capital }\end{array}$ \\
\hline 12 & Team of MEE project & Project management & A & $\begin{array}{c}\text { The image of the team and } \\
\text { its members }\end{array}$ \\
\hline 13 & Suppliers of energy efficiency solutions & Supplier & A & Profit, image \\
\hline 14 & Contractors - designers & Performer of work & $\mathrm{L}$ & Profit, image \\
\hline 15 & Contractors of installation of systems & Performer of work & $\mathrm{L}$ & Profit, image \\
\hline 16 & Service companies as contractors & Performer of work & $\mathrm{L}$ & Profit, image \\
\hline 17 & Scientific institutions & Performer of work & $\mathrm{L}$ & Profit, image \\
\hline 18 & Independent experts & Service provider & $\mathrm{L}$ & Confirmation of experience \\
\hline
\end{tabular}

\section{Research results of proactive model and method of energy efficiency projects}

Based on the established principles, let's propose a method for proactive communication of the MEE project management system with stakeholders in the sequence of the following steps (Fig. 1). 


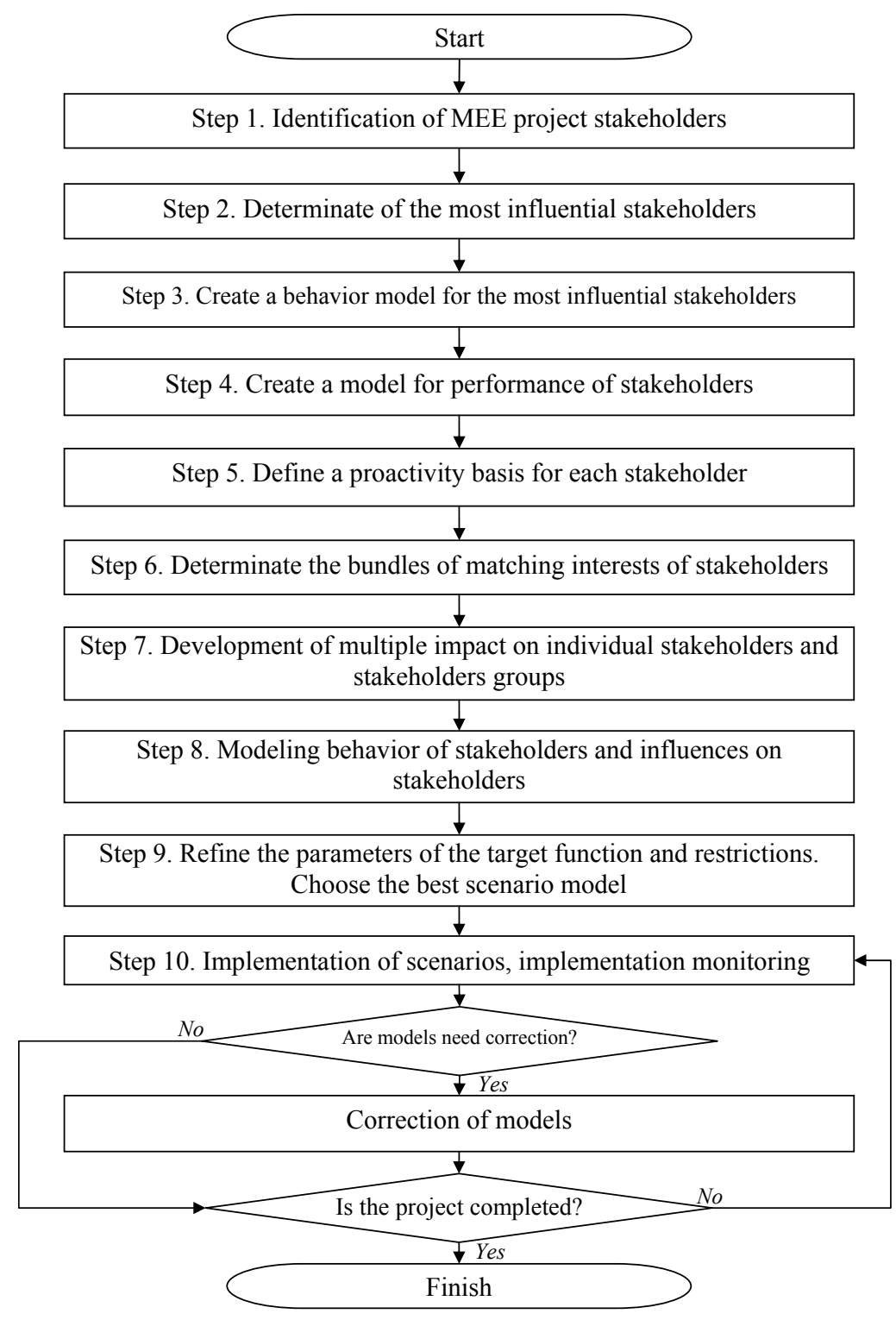

Fig. 1. The method of proactive communication of the project management system of municipal energy efficiency with the stakeholders (own source)

1. Identification of MEE project stakeholders.

The management system of MEE project, in the person of the project team, should determine the F set of all stakeholders who are interested in the results of the MEE project or during its implementation and may in some way influence the MEE project. Stakeholder interest may have a different sign and range from the strong resistance of the MEE project to its strong support.

Formalizing the interest of $\mathrm{Z}$ stakeholders $\mathrm{F}$ in the framework of the theory of fuzzy sets, let's formulate: $\forall \mathrm{F}^{\mathrm{i}} \exists \mathrm{Z}_{\mathrm{i}}, \mathrm{Z}_{\mathrm{i}}=\{$ “strong resistance", "resistance", "low resistance", "neutral attitude", "insignificant support", "support", "full support"\}.

2. Determinate of the most influential stakeholders of MEE project.

Of the whole set $\mathrm{F}$ of all stakeholders of the PME project by the expert group assessment method, a set of the most influential stakeholders is allocated $\tilde{\mathrm{F}}$.

3. Create a behavior model for the most influential MEE project stakeholders.

According to the results of the previous activity $\tilde{\mathrm{F}}$ of the most influential stakeholders is their behavior model, and: 


$$
\tilde{\mathrm{F}}^{\mathrm{i}}=\left\{\tilde{\mathrm{F}}_{1}^{\mathrm{i}}, \tilde{\mathrm{F}}_{2}^{\mathrm{i}}, \tilde{\mathrm{F}}_{3}^{\mathrm{i}}(\mathrm{j}, \mathrm{k})\right\},
$$

where $\tilde{\mathrm{F}}_{1}^{\mathrm{i}}$ - the set of values of the i-th stakeholder; $\tilde{\mathrm{F}}_{2}^{\mathrm{i}}$ - the set of strategies of the i-th stakeholder; $\tilde{\mathrm{F}}_{3}^{\mathrm{i}}(\mathrm{j}, \mathrm{k})$ - the set of behavioral characteristics of the $\mathrm{i}$-th stakeholder, which is reflected by its $\mathrm{k}$-th typical reaction to the $\mathrm{j}$-th typical situation.

4. Create a model for performance of stakeholders - their influence on the MEE project.

Next, it is necessary to determine the structure of the results of the stakeholder activities in conjunction with the MEE project, which is expressed as:

$$
\overline{\mathrm{F}}^{\mathrm{i}}=\left\{\overline{\mathrm{F}}_{1}^{\mathrm{i}}, \overline{\mathrm{F}}_{2}^{\mathrm{i}}, \ldots, \overline{\mathrm{F}}_{\mathrm{L}}^{\mathrm{i}}\right\},
$$

where $\mathrm{L}$ - number of activity results of the i-th stakeholder, which is estimated.

5. Define a proactivity basis for each stakeholder.

The points of application of $\dddot{\mathrm{F}}^{\mathrm{i}}$ influence on Stakeholders $\tilde{\mathrm{F}}^{\mathrm{i}}$ by the MEE project are identified, that is, aspects that may be influenced by the project management system to guide the activities of the owner of the project in the direction of support of the project.

6. Determination the bundles of matching interests of stakeholders, which are potential catalysts for the development of the project (support centers), and bundles of matching interests of stakeholders, which are potential inhibitors of the project development (resistance centers). That is, the structuring of a plurality of stakeholder values $\left\{\left\{\tilde{\mathrm{F}}_{1}^{1}, \tilde{\mathrm{F}}_{1}^{2}, \ldots, \tilde{\mathrm{F}}_{1}^{\mathrm{n}}\right\},\left\{\tilde{\mathrm{F}}_{1}^{\mathrm{n}+1}, \tilde{\mathrm{F}}_{1}^{\mathrm{n}+2}, \ldots, \tilde{\mathrm{F}}_{1}^{\mathrm{n}+\mathrm{m}}\right\}, \ldots\right\}$.

7. Development of multiple impact on individual stakeholders and stakeholders groups how can the project management system be influenced by directing the stakeholder to the project support. That is, the development of a set of impacts $\overline{\bar{F}}^{i}$ of the MEE project management system on a separate i-th stacker and the set of impacts $\overline{\bar{F}}^{\mathrm{G}_{j}}$ of the MEE project management system on the $\mathrm{j}$-th group of stakeholders, whose values coincide.

8. Modeling behavior of stakeholders and influences on stakeholders. There is a simulation of the behavior of stakeholders, the bundles of emerging stakeholders' interests and impacts on them. According to the simulation results, a set of scenario models of the behavior of the management system are formulated. That is, matching compliance:

$$
\tilde{\mathrm{F}}^{\mathrm{i}} \rightarrow \overline{\overline{\mathrm{F}}}^{\mathrm{i}},\left\{\tilde{\mathrm{F}}_{1}^{1}, \tilde{\mathrm{F}}_{1}^{2}, \ldots, \tilde{\mathrm{F}}_{1}^{\mathrm{n}}\right\} \rightarrow \overline{\overline{\mathrm{F}}}^{\mathrm{G}_{\mathrm{j}}},
$$

where $\overline{\bar{F}}^{i}$ - impact of MEE project management system on a separate i-th stakeholder; $\overline{\bar{F}}^{G_{j}}-$ the impact of the MEE project management system on the j-th group of stakeholders, the values of which coincide.

9. Refine the parameters of the target function and constraints. Choose the best model from the set of scenario models. The target function for the MEE project can be formulated as maximizing the positive effect of cooperating with stakeholders of the MEE project and for each individual project may have different content. Constraints will be the budget for the implementation of interaction with stakeholders and the timeline of the project.

10. Implementation of scenarios, implementation monitoring. Correction of models.

There is tracking the behavior of MEE project stakeholders, implementation of developed scenario models of project MEE management system. In this case, monitoring of the implementation of scenario models and their correction, if necessary, should be monitored.

\section{Results and discussion}

The research presented in this article is a logical continuation of the work of the authors [19-21] on the formalization of models and methods of energy efficiency projects for municipal infrastructure.

The conducted studies give the opportunity to formulate the main advantages that can be obtained by using their results. The results will allow to:

- systematize knowledge of stakeholders on projects for ensuring municipal energy efficiency; 
- take into account the prediction of the behavior of the project stakeholders;

- plan proactive actions in conjunction with project stakeholders to avoid their negative impact on the project;

- take into account the interaction and cross-over of the stakeholders of the project to increase municipal energy efficiency.

The disadvantage of the results is that it is impossible to manage reputational aspects of municipal energy efficiency projects with their help.

The results of research on proactive communication with stakeholders were introduced in the district administration of the city of Kyiv. The stakeholders of MEA projects have been identified. The most influential stakeholders have been identified in accordance with the developed method of proactive communication. According to the results of the analysis, they are the following stakeholders: local community, condominiums, organizations of public control, private investors, and project executors. According to the results of modeling the activity of stakeholders, relationships between stakeholders have been identified. Based on the results of the analysis of such relationships, a communication model has been proposed, in which some of the links have been removed, some have been left, and some have been added (Fig. 2). The basis for proactivity for identified stakeholders has been identified as a combination of enhancing the image and positive resonance of society. As a result of the introduction of the proactive model and method, the efficiency of engagement stakeholders to the project has been ensured. In particular, the percentage and number of positive comments from the local community and condominiums significantly increased, while the feedback from private investors was less frequent, but the degree of satisfaction of the stakeholder has increased, as well as the level of its support for the project.

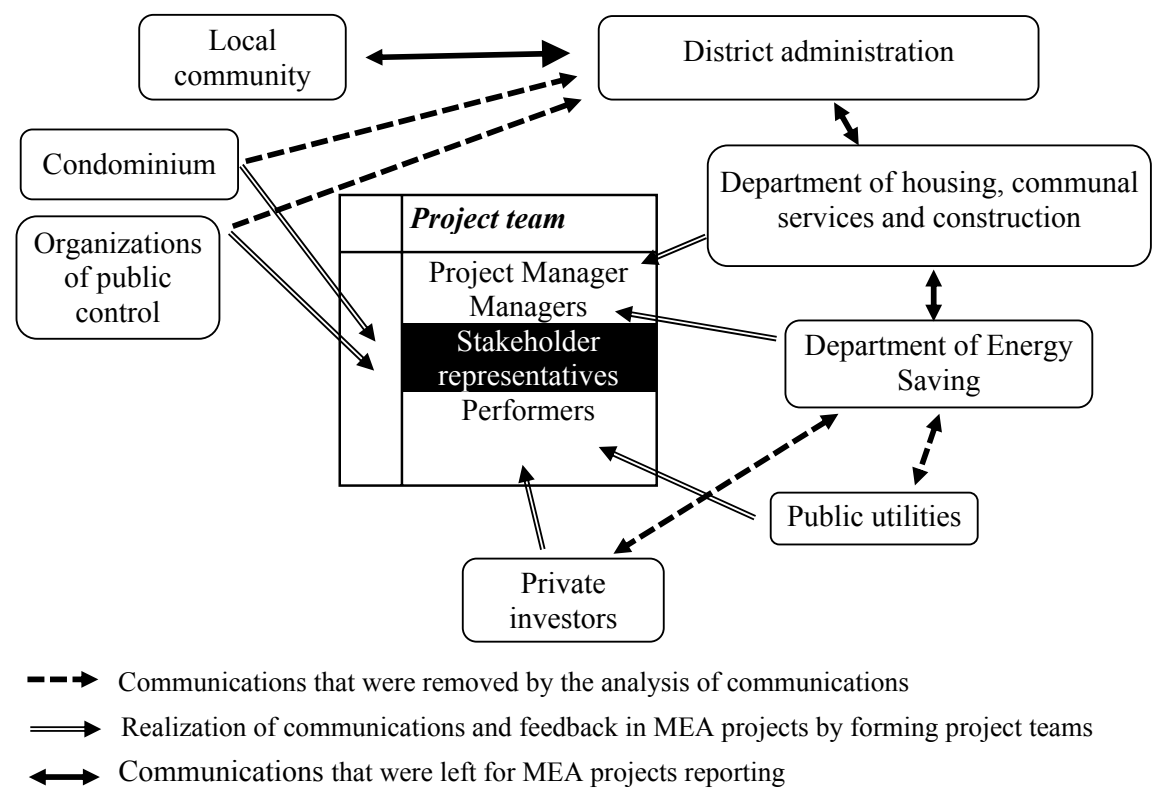

Fig. 2. Communications in MEA projects (own source)

The usefulness of the developed model, principles and method of proactive communication of the MEE project management system with the stakeholders is that these results together will ensure the effective operation of the decision-making system in the project of ensuring municipal energy efficiency.

Research in the chosen direction is advisable to continue in line with the implementation of the developed model and method in the form of an algorithm and program implementation.

As a result, communication issues of stakeholder interaction have been solved: the whole complex of expectations of stakeholders has been taken into account; the specificity of MEA projects has been taken into account, the proactivity has been allowed to predict the impacts of the 
stakeholders and develop action to prevent negative impacts. This allows to conclude that the goal of the study has been achieved.

\section{Conclusions}

According to the results of the research on the development of proactive method of communications for projects of ensuring the energy efficiency of municipal infrastructure, the following conclusions can be formulated:

- application of the principle of proactivity to communication in the municipal energy efficiency projects with the project stakeholders is investigated; the definition of the basis for proactivity is proposed, the possible roles of stakeholders in the projects are determined;

- model of stakeholders of MEE project is developed taking into account the proactive influence on them; the model defines a proactivity basis for each stakeholder;

- method of proactive communication of the MEE project management system with the stakeholders is proposed; The scheme of implementation of the method is given.

The peculiarities of the concept proposed in this article are the application of the proactivity principle to communicational management of the project to increase municipal energy efficiency. Due to this, it is possible to provide stakeholder's behavior prediction and development of prevention actions of stakeholder's negative influences on the project. The two most important factors to resolve problems, which are identified in the introduction: taking into account the whole range of stakeholder impacts (which allowed for a more precise management response) and forecasting behavior of stakeholders (this allowed to reduce project risks and ensure project implementation within the specified constraints). Because of the developed results approbation, the effectiveness of the project's energy efficiency improvement with stakeholders has increased. The degree of opposition from the stakeholders has decreased. This allows improving the quality of project management and reducing the lag in project implementation terms.

\section{References}

[1] A Guide to the Project Management Body of Knowledge (PMBOK® Guide) (2017). USA, Project Management Institute, 756.

[2] Greenley, G. E., Foxall, G. R. (1997). Multiple Stakeholder Orientation in UK Companies and the Implications for Company Performance. Journal of Management Studies, 34 (2), 259-284. doi: https:// doi.org/10.1111/1467-6486.00051

[3] Roloff, J. (2007). Learning from Multi-Stakeholder Networks: Issue-Focussed Stakeholder Management. Journal of Business Ethics, 82 (1), 233-250. doi: https://doi.org/10.1007/s10551-007-9573-3

[4] Selander, J. (2008). Stakeholder management: management of interest groups. Human Resources Manager, 3. Available at: http://hrliga.com/index.php? module=profession\&op=view\&id=844

[5] Bushuyeva, N. S. (2007). System dynamics on the model of centers of influence in organizational development projects. Project management and development of production, 1, 29-33.

[6] Ammary, A. O. (2012). Classification of stakeholders on the basis of mutual occouvans. Actual problems of economics, 8, 150-155.

[7] Lukashenko, V., Lepskyi, V. (2017). Principles of integrated management of threats to provide the values of stakeholders of project-oriented medical institution. Management of Development of Complex Systems, 32, 42-49.

[8] Prokopenko, O. V., Shkola, V. Yu., Shcherbachenko, V. O. (Eds.) (2017). Management of the innovative component of economic security. Interaction of Stakeholders of Regional Development Projects' Portfolios in the Context of Ensuring Economic Security of Ukraine. Sumy.

[9] Bateman, T. S., Crant, J. M. (1993). The proactive component of organizational behavior: A measure and correlates. Journal of Organizational Behavior, 14 (2), 103-118. doi: https://doi.org/10.1002/ job.4030140202

[10] Crant, J. (2000). Proactive behavior in organizations. Journal of Management, 26 (3), 435-462. doi: https://doi.org/10.1016/s0149-2063(00)00044-1 
[11] Parker, S. K., Collins, C. G. (2008). Taking Stock: Integrating and Differentiating Multiple Proactive Behaviors. Journal of Management, 36 (3), 633-662. doi: https://doi.org/10.1177/01492063 08321554

[12] Bushuyeva, N. S. (2014). Mechanisms of matrix technologies of the proactive balanced management of organizational development programs. Project Management and Development of Production, $2(50), 96-106$.

[13] Vorkut, T. A. (2016). Proactive program management of regional road transport systems. Kyiv, 171.

[14] Bushuyev, S. D. (2008). Proactive management of organizational development programs. Kyiv, 68.

[15] Chornous, G. O. (2014). Proactive management of socio-economic systems on the basis of intellectual data analysis. Methodology and models. Kyiv, 351.

[16] Itchenko, D. M. (2015). Analysis of approaches to proactive management in the context of their usage while AIC projects and programs realization. Bulletin of NTU "KhPI". Series: Strategic management, portfolio management, program and project management, 2 (1111), 141-148.

[17] Savelyeva, O., Berezovskaya, E., Monova, M., Heblov, I. (2016). The thermodynamic criterion analogy using for decision support in the management of project risks. Proceedings IX Annual scientific conference «Information technology and automation - 2016», Odessa, 14-15.

[18] Buysse, K., Verbeke, A. (2003). Proactive environmental strategies: a stakeholder management perspective. Strategic Management Journal, 24 (5), 453-470. doi: https://doi.org/10.1002/smj.299

[19] Shkuro, M., Bushuyev, S. (2017). Application of project management in municipal infrastructure projects for energy efficiency. Bulletin of Lviv State University of Life Safety, 16, 76-82.

[20] Shkuro, M. (2018). Creation of a corporate project management system for improving the energy efficiency of municipal infrastructure. Proceedings of the 3rd International Conference «Science and society - Methods and problems of practical application». Accent Graphics Communications \& Publishing, Hamilton, Vancouver, 117-119. doi: https://doi.org/10.29013/iii-conf-canada-3-117-119

[21] Shkuro, M. (2018). Conceptual model of project management system for increasing municipal energy efficiency. Herald ChSTU. Series: Engineering, 2, 76-81. 